\title{
Planning Mobility on Transboundary Shrinking Towns
}

\author{
Luciano Alfaya, CESUGA, Universidad San Jorge, Spain \\ Patricia Muniz, Universidade da Coruña, Spain \\ David Wilkes, Estudio MMASA, Spain \\ Antia Martinez, Estudio MMASA, Spain \\ Camilo Fernandez, Inzarede, Spain
}

\begin{abstract}
Mobility plans have become an essential instrument for the urban planning of cities. Compared to other documents and by focusing on the improvement of public spaces, these plans can work as strategic documents for cities of diverse scales, especially in municipalities that decrease and consequentially cannot trust their reorganization to new developments. This article poses the double objective of assessing the differences between proximity planning in five plans carried out in small-size Spanish municipalities, and spatial planning in the Galicia-North of Portugal transboundary plan. To this end, the results of the surveys carried out and the origin-destination matrixes are analyzed, looking closely at the similarities obtained between the digital and the on-site data. Therefore, it is possible to confirm that the digital data is useful regarding urban planning for territories with dispersed population, even where two countries are involved.
\end{abstract}

\section{KEYWORDS}

Galicia, Portugal, Strategic Planning, Sustainable Mobility, Transboundary, Urban Planning, Urban Recycling, Urban Tools

\section{INTRODUCTION}

For years urban planning has centered on the increase of the cities. At a global level it is still a generalized phenomenon (Burdett, 2011). But not all cities grow. Many even, also of a small scale, are constantly losing population with no prospect of change of trend (Lois \& Pino, 2015). In this regard, the planning of urban mobility is an essential public tool, without being subject to private development and without reaching the level of an urban project.

This article is centered on the analysis of different mobility plans in small size municipalities (between 3,000 and 10,000 inhabitants approximately), located in the province of Pontevedra, in the Northwest of Spain. These are municipalities that, as a consequence of the processes to obtain community funds, especially FEDER funds, have been forced to draft documents regarding mobility improvement which guarantee a reduction of emissions to the atmosphere. 
Further on, the results of these specific approaches will be compared to a more territorial, multiscale, and cross border vision. It is a total area of over 200,000 inhabitants in the north of Portugal, and a total of 16 municipalities.

All these small towns are aware that their problems do not lie in, and cannot be solved, by improving urban mobility, therefore, from the outset, the drafted documents respond to far-reaching problems (Ezquiaga \& Alfaya, 2011).

At the outset, it is worth noting that all the plans introduced, were all done under our supervision, have been approved in the last few months and the data corresponds to 2019. On the other hand, as will be described further on, these plans are intended to surpass the basic optimization of circulation flows and to focus on the development of a strategic vision of the territory, using the redefinition of public spaces to this end.

At a Galician level this phenomenon of mobility planning in small municipalities is quite recent, so, beyond territorial analysis associated to the reliance on the main cities (Harguindey, 2011), no special studies at a territorial level have been made. The cross-border problem had been addressed by Carballo Lomba (2015), also by Palmero and Pazos (2008), from the certainty of a lack of vision which surpassed the limits of each of the countries.

Recently, the Strategic Plan of the cross-border Area Galicia-North of Portugal, carried out by geographers of the University of Santiago de Compostela, and as yet not published, sets out a vision for all the cross-border territory. It also places mobility as the articulating seed of future actions.

The relevance of this article is also reflected in the proliferation of mobility plans. Barely a year ago, no municipality of less than 20,000 inhabitants in the province of Pontevedra had a mobility plan. By 2020 almost fifty will have made theirs.

The reference manuals - academic or managerial- are centered on the functional structure of the big cities. The condition of small municipalities -larger in number and in all the territory- makes it necessary to make a critical assessment of the parameters pointed out in these reference manuals, as they do not have a coherent reference for small scale.

In any case, assuming that the urban planning regulations have always been associated with the city growth, the transversal question that is intended to be developed in this article is the following: How to plan towns and small settlements, especially when they are losing population?

In order to get a coherent answer, we will need to understand movement patterns. Origindestination matrixes are needed, but also an understanding of what motivates displacements. A preliminary step to achieve this is comparing results obtained on-site with those obtained through online surveys. It will then be possible to obtain ideas for future projects in municipalities with shrinking dynamics. Therefore, a comparative analysis between over 5000 surveys is made. The data is separated in order to extract further estimations of the process.

The objectives that are proposed are basically two: To demonstrate the parallelisms between the results obtained in one process or the other; To identify the differences between the surveys made in specific municipalities and the surveys made in a territorial area of a bigger size.

\section{THE FIELD OF STUDY: AN X-RAY OF THE TERRITORY}

After a period of urban excess in Spain, and an immediate period in which it seemed that the only thing that was relevant was the future of underdeveloped lands, there has been a social debate about the risks of the demographic decline and the loss of population, especially in small-size towns and villages.

Although this takes place in many dimensional levels, there is a significant belt of populations, primarily in the context of between 5,000 and 10,000 inhabitants, in whose dichotomies we can find opportunities for the ecological and social rebalancing, combined with enough capacity of attraction. Municipalities which are found in the margins of what we would normally consider to be urban, and 
that everyday lose more population, are further stigmatized by being categorized (Richardson, 2014). They reinforce the challenge to find mechanisms to attract new residents.

Nowadays, according to data of the 2018 INE, $90 \%$ of the Spanish municipalities have a population of less than 10,000 inhabitants, although there are only 9.6 million people living in them (20\% of the residents). Nevertheless, the loss of population in the last few years has been scarce, and it is quite uniform in all population belts. This normally makes up urban or metropolitan areas of larger cities (Figure 2).

Small municipalities have a high standard of living in important aspects, such as pollution and the security of citizens, but they essentially depend on their strategic capacity to position themselves in a context of multiple similarities between all of them. Normally, they are municipalities with a reduced population density, but enough in most cases, to preserve some proximity resources. Also, basic endowments, which live together with certain agricultural ties. They help to guarantee a social development of the community.

Therefore, the change of paradigm seems to be found first and foremost, in the planning of these towns and cities. For years, the mechanisms of urban approach in Spain -and in general in the south of Europe- regarded urban growth as a basis for the transformation of the city. Nowadays when the city decreases all mechanisms associated with the expansive model lose validity.

In any case, assuming that the ultimate objective of urban planning is building better places (Healey, 2010) for the users of the city, it becomes necessary to define which of these mechanisms will allow the correct choice of intervention priorities. Also, which will be the measuring tools, knowing that once again, for those who have no previous feelings for a place, the causes for displacement can only be interested or provoked. It is difficult to imagine both scenarios for this level of towns, though they cannot be therefore discarded, if specific conditions are created.

For all this, the planning of mobility becomes essential. These are moments when the development of the conventional planning is frequently entrenched, and in which only a small number of urban plans are approved definitively. Additionally, the obstacles that exist for the supra-municipal planning - and more for the supra-state - seem to compel giving an isolated answer for each municipality without taking into account the neighboring territory.

In a context of sprawl, where the borders between the rural and the urban lack meaning, (as defined by Domingues in 2003), we find ourselves in a "transgenic" territory. There is a unique opportunity to develop proposals without a compelling frame, nor being subjected to strict regulations.

For the five municipalities of scarce population which are part of the study, and which will be later described, sustainable mobility plans have been developed. As it seems obvious, under these circumstances, the plans, more than solving traffic circulation problems, assume the challenge of redefining the behavior of the most active spaces of the municipality, as well as their relationship with other attraction centers in the surroundings.

On the other hand, the transboundary Plan of Sustainable Mobility is developed from a territorial scale, covering a scope of over 100,000 persons, but solving similar problems. The largest of the municipalities that are directly affected hardly exceeds the 15,000 residents.

The analysis is done over a group of five municipalities with different population (Table 1): Caldas de Reis, 9,860 inhabitants; Silleda, 8,698 inhabitants; Soutomaior, 7,305 inhabitants; Pazos de Borben, 2,980 inhabitants; and Covelo, 2,417.

This is about municipalities, all of them of less than 10,000 inhabitants, who in the last years have lost population. The case of Covelo stands out, with a continuous loss of residents since the 80's. On the other hand, Soutomaior has hardly been losing population since 2014 (7.356 inhabitants), after a significant growth during the period of the property bubble in Spain (located in the limit of the municipality of Pontevedra, of almost 100,000 inhabitants). To put it in context, in these last ten years, at a territorial level, Galicia lost around 3\%, while the province of Pontevedra has lost a little over 1\%.

The field of study, then, includes five municipalities with the customary parameters of slight loss of population (more marked the more they are located inland and away from communication main 
Table 1. Evolution of population over the last 37 years in five municipalities with different population numbers. Source: Prepared by the author and IGE.

\begin{tabular}{|l|l|l|l|l|l|l|l|l|}
\hline & \multicolumn{1}{|c|}{$\mathbf{1 9 8 1}$} & $\mathbf{1 9 9 1}$ & $\mathbf{2 0 0 1}$ & $\mathbf{2 0 0 8}$ & $\mathbf{2 0 1 1}$ & $\mathbf{2 0 1 8}$ & \multicolumn{1}{c|}{ TOTAL } & 10 Years \\
\hline Caldas de Reis & 8.889 & 9.176 & 9.453 & 9.975 & 10.060 & 9.860 & $+10,92$ & $-1,15$ \\
\hline Silleda & 10.363 & 10.021 & 9.175 & 9.166 & 9.199 & 8.698 & $-16,07$ & $-5,11$ \\
\hline Soutomaior & 5.539 & 4.959 & 5.398 & 6.537 & 7.223 & 7.305 & $+24,17$ & $+10,51$ \\
\hline Pazos de Borbén & 3.801 & 3.500 & 3.089 & 3.178 & 3.192 & 2.980 & $-21,60$ & $-6,23$ \\
\hline Covelo & 6.766 & 4.440 & 3.968 & 3.457 & 3.235 & 2.417 & $-64,28$ & $-30,08$ \\
\hline
\end{tabular}

roads). Of these, Covelo stands out, the municipality of the province with the highest decrease of population in almost 40 years. Thus, as it was pointed out, these municipalities have taken advantage of the invitation to be able to define a strategic vision for the territory. This is effective in order to develop new actions that contribute to stabilize the existing population.

Under this situation of interest to formulate the mobility plans, the province administration, as part of the program of transboundary action INTERREG in Galicia and the North of Portugal, has requested the drafting of the Transboundary Sustainable Mobility Plan of the Minho River (Figure 1). This is a project that, taking the development of the different municipal plans in the province as reference, raises the importance of mobility to promote the connection between the north of Portugal and the south of Galicia.

Figure 1. Municipalities from South of Galicia and North of Portugal separated by the Minho River. This is where the mobility plan has been done. Area of the Transboundary Minho. (c) 2019, Author.

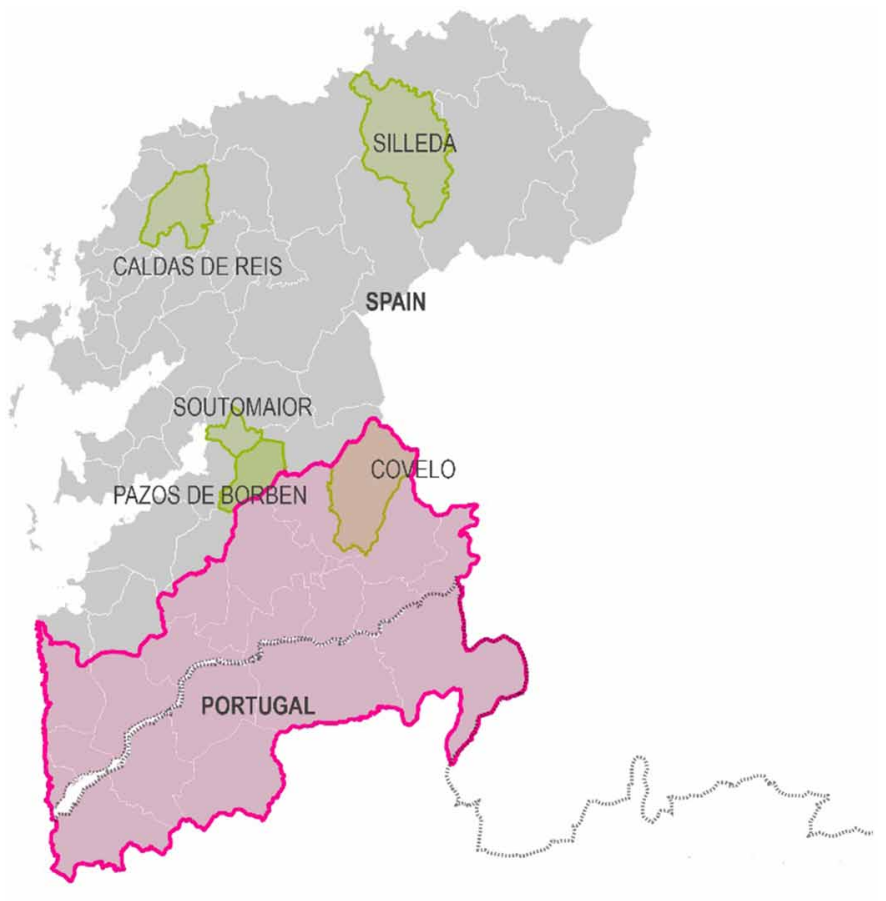




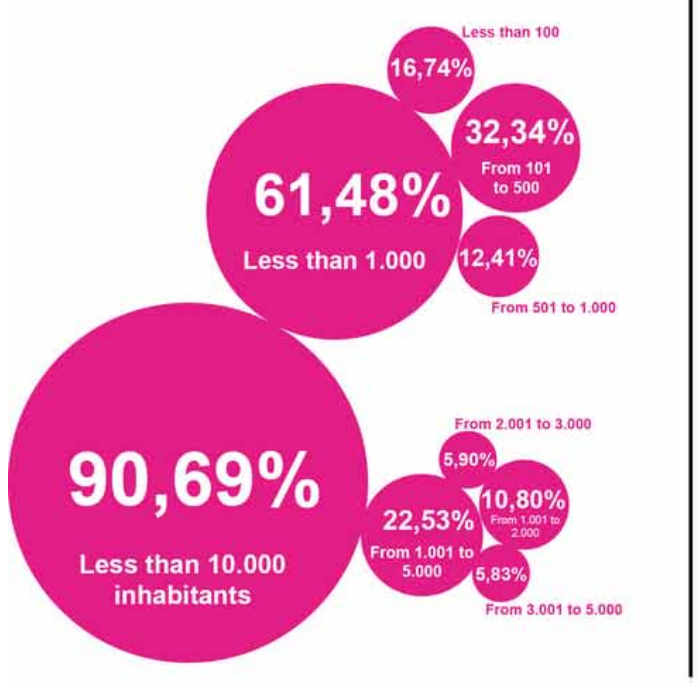

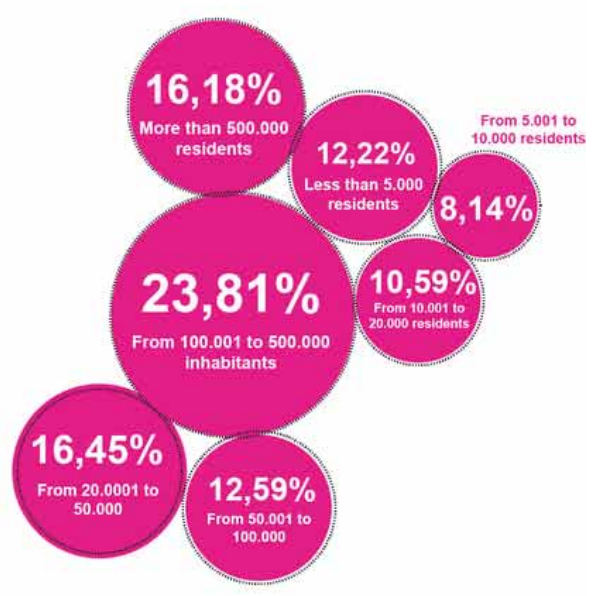

Projects are being done under the encouragement of the European Group of Territorial Cooperation of the Minho River, which may contribute to improve fluency between both countries. Also, to enhance the shared projects, and guarantee the cooperation between towns on both banks of the Minho River, dividing the actions between both.

It is an area that has nearly 400,000 inhabitants divided over 26 municipalities, of which 18 are in direct contact with the Minho River and where almost half of the population are concentrated. As can be inferred, the average size of these municipalities is around 10,000 inhabitants, without any of them, on the axis of the river itself, being understood as a main node.

This might be why for a few years now euro-cities have been promoted. It is an agreement between twinned towns (Moncao-Salvatera, Valenca-Tui, \& Vilanova de Cerveira-Tomiño) that establish joint actions and proceedings without a legal frame which allows them to act legitimately.

It is under this context that the Transboundary Plan of Sustainable Mobility of the Minho River (TPSM) was made. A plan, that just as the municipal ones, cannot be considered to impose any specific transformation, but that leads the way for further interventions, and sets the guidelines for the future.

\section{PRIORITIES OF STRATEGIC PLANNING THROUGH MOBILITY}

Most of the proposals of ecological urbanism (Rueda et al, 2014), are usually articulated around a reduction of consumption of resources. On this basis, the improvement of urban mobility is an essential starting point, and maybe the one that offers a greater immediacy, and a more favorable ratio between investment and results.

It is a starting point, as through mobility, with restrictions and activation of spaces, certain places can be given value, and the arrival to others mitigated. It is immediate, because mostly it only affects public space, without the need for the entry of private owners, nor excessive bureaucratic paperwork. And it offers an interesting relationship between investment and results, because of micro-actions of tactical character - such as the painting of the ground, or certain occupations - it is possible to start the assessment of the viability of the operations (Holl, 2009). 
Since 2014, the European Union, with FEDER funds, has been progressively insisting on the relevance of adequately planning the urban interventions, in such a way that indicators that validate the investments made can be established. In this process, formulating mobility plans is understood as a first step in Plural Urbanism (Ryan, 2017) with the reconfiguration of the public space, which, having the recovery of the centrality of pedestrians as a priority objective, also involves a reflection about the attracting centers and the connection axes among them in order to achieve an adequate urban and territorial rebalancing.

This generalized shift of paradigm has reversed the focus of previous decades where the priority was to guarantee the fluidity of vehicles circulation with two objectives: reducing driving time, or, as some authors point out (Pozueta, 2009), driving the same amount of time but covering a longer distance. The first objective meant introducing in the towns, in their corresponding scale, spaces reserved for the circulation of vehicles (from large dimension roadways to viaducts) generating a fragmentation in the spaces for pedestrians, subordinated to these infrastructures. The second approach has consolidated, in the big towns, the sprawl of single-family homes and in the small towns, a growth in the neighboring municipalities, with cheaper land and hardly any services.

In the case study a third scenario is raised, one that is characteristic of the Euroregion NorthGalicia of Portugal: the diffuse city (Dalda et al, 2006). In this case there is neither the great dimension of American cities, nor is it about adjacent municipalities with average cities. These are settlements in a dispersed territory, lacking defined attractors, and upon which intermediate-size roads cross conditioning them, but which, in no case, have the municipality itself as an objective.

Three of the municipalities analyzed have been crossroads between average towns (between 100,000 and 250,000 inhabitants): Caldas de Reis between Santiago de Compostela and Pontevedra, Silleda between Santiago de Compostela and Ourense, Soutomaior, and specifically Arcade, between Pontevedra and Vigo. The other two, Covelo and Pazos de Borben, have been excluded from those roadways, thus the loss of population has become more evident by not being able to depend on larger cities. These municipalities, all of them with an updated urban planning, have had very limited approaches in terms of strategic planning and mobility, limiting their documents to act as an answer to the current situation.

Writing mobility plans has become a binder which is part of a mandatory objective on global consensus (reduction of $\mathrm{C} 02$ emissions to the atmosphere). It is to be developed through an integrated process (in which participation has a relevant role, conditioning the development of some areas), and conclude as an instrument to obtain resources (allowing the implementation of projects, which, at the end of the cycle, will imply the reduction of emissions).

The current generation of Mobility Plans, thanks to their integrated process and cross-disciplinary writing, includes at least three visions in a holistic way. On the one hand, the presence of vehicles, both public and private, is modified both by their intensity as well as by the changes being introduced in motor vehicles (Sumantran et al, 2017), making them more efficient and ecological (all being aware of the proximity of significant changes in ways of commuting). But, as has been mentioned before, the mobility plans are not made to improve traffic times, rather they must mainly focus on the generation of spaces for people. That is why many of the necessary indicators consider these parameters as the most relevant in the process. And the third vision, included in the optimization of the mobility, and the improvement of public spaces, is the protection of the environment. This focal point is especially binding to claim the need to have coordinated and complementary actions, instead of isolated interventions in the city (Corburn, 2009).

In the transboundary context the situation is obviously more complex. In the first place because the visions in Spain and Portugal are now different. Planning in the Portuguese country has an intense work of strategic vision which has decreased in the Galician municipalities being centered on the legal certainty of the document and their relative implications to the property value. Additionally, each municipality, which in most of the cases exceeds the 10,000 inhabitants, have mobility plans 
done in a vacuum, without considering the interactions with adjacent municipalities, and least of all, the towns on the other side of the river.

\section{PROCESS TO OBTAIN DIGITAL AND ON-SITE INFORMATION}

The process to obtain data was done through the combination of several documentary sources: databases and georeferenced downloads, measurements of the land, semi-structured interviews, workshops, and on-line and on-site surveys. All the information turned out to be relevant, but in this context of urban e-planning, we would like to make a halt in the mechanisms to obtain the georeferenced data, and on the other hand, on the methodological approach to make the same survey through digital and analogical means.

Regarding the collection of alphanumerical and geographical/cartographical data used to formulate mobility plans, their access is fundamentally free both in the central management and above all, on the autonomous management.

Nevertheless, the complexity to obtain data on the Portuguese side has been significant, in spite of the Inspire regulations, a legal initiative that establishes technical standards and protocols, organization and coordination aspects, policies about information, which include the access to data and the creation and servicing of spatial information.

In this context, in the case of Galicia, more specifically for the province of Pontevedra, to which the municipalities that pertain to the territory of application belong (Minho Transfronteirizo), the process to obtain data is relatively simple. Nevertheless, for the municipalities of the north of Portugal, this process is complicated due to the lack of access to this type of information and data. This problem in the availability of data turns out to be an important handicap in the execution, due to the impossibility of unifying information on both sides of the border.

As an example, in this case, the first obstacle is the impossibility to obtain the same data in all the periods (Table 2). Especially those of a separate character due to administrative subdivisions in the municipality. Thus, even when in Portugal they have the level of freguesía, and in Galicia the one of parrish, which are comparable when unifying criteria, the dates of data updating are not the same. Even if there is separate data, many of the diagnosis are done at a municipal level in order to have an objective comparison.

This is of great relevance, as one of the inexistent data in Portugal since 2011 is the evolution by freguesía, and this is significant information in order to analyze the depopulation processes in

Table 2. Sources from organisms that have provided information and data that has been used for the formulation of the transboundary mobility plan

\begin{tabular}{|l|l|l|}
\hline \multirow{5}{*}{ Spain } & \multicolumn{1}{|c|}{ Alphanumerical Data } & \multicolumn{1}{c|}{ Spatial Information } \\
\hline & Instituto Galego de Estatística & Instituto Xeográfico Nacional \\
\cline { 2 - 3 } & Instituto Nacional de Estadística & Información Xeográfica de Galicia \\
\cline { 2 - 3 } & & $\begin{array}{l}\text { Sistema de Información de Ordenación do Territorio e } \\
\text { Urbanismo de Galicia }\end{array}$ \\
\cline { 2 - 3 } & & Dirección General de Catastro \\
\hline \multirow{3}{*}{ Portugal } & Instituto Nacional de Estatística & Direção Geral do Territorio \\
\cline { 2 - 3 } & & Sistema Nacional de Informação Geográfica \\
\hline \multirow{3}{*}{ International } & & Geoportal INSPIRE \\
\cline { 2 - 3 } & & Geostat \\
\cline { 2 - 3 } & & USGS \\
\hline
\end{tabular}


the municipalities, because as, shown in Figure 3, the inland settlements are suffering an emptying process. There is a concentration towards the municipal capitals and to those heartlands closest to the main roadways.

In the second place, in the Portuguese case, there is no possibility to access a free download service of orthophotos, but there is the opportunity of open consultation of aerial images - and their evolution since 1956 - in Galicia.

Figure 3. Map of the evolution of population over the last 10 years, in the area of the transboundary mobility plan. Red for municipalities with population loss, and blue for municipalities with population growth. ( $) 2019$, Author.

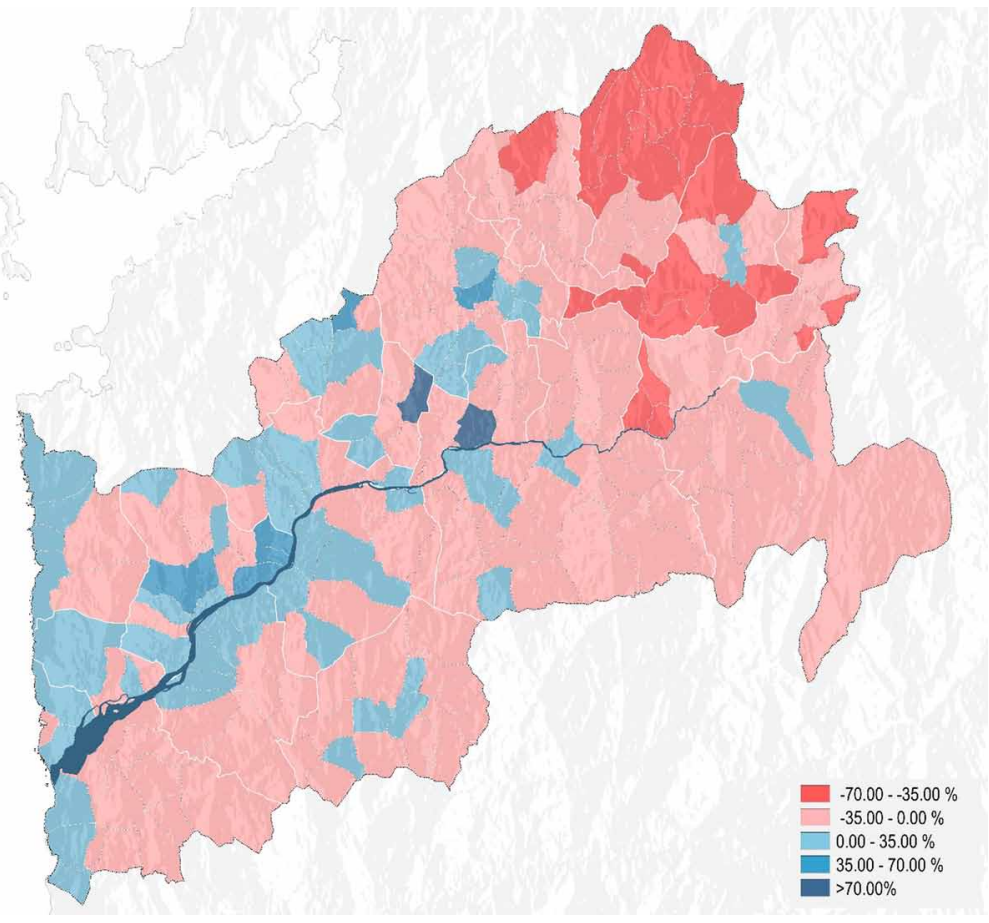

Finally, the impossibility to obtain cadastral information because of constructions or parcels of land, and the information relative to public transportation lines was detected. This information in both cases is available for the Spanish municipalities of the Minho River.

In the end, the availability of alphanumerical and cartographic data in Portuguese portals for free download is very limited, having to access them through other geoportals which belong to international entities.

The result of this difference in contents, is the reduction in the use of sources of information through different websites, and an important increment in the fieldwork. Especially surveys to make origin-destination matrixes, which guarantee the obtention of the same data in both sides of the border.

As a consequence of all the difficulties explained, the data acquisition through surveys became essential, and stricter control and follow-up of the latter was established. On the one hand, an autonomous website was created to manage the data obtained and enable its interrelation with the team of sociologists. An adequate dissemination was guaranteed through the social networks of the municipalities themselves, and by establishing contacts with organizations and groups, who were invited to participate in the sector-based tables. 
On the programming level, a visual interface was meant to be created, which, in spite of the complexity of the data intended to be obtained, would not seem complex to the users. To this end, a general introduction was made - which included the acceptance of the privacy of the data obtainedand then a single screen for the survey divided into three types of questions: general valuations, open contributions, and registration of commutes (origin-destination matrixes). Admittedly, a control to prevent bots was established, in such a way that only one answer could be accepted from each IP address- which at some point may have penalized answers from the same work center.

Regarding these three areas -valuations, open contributions, and matrixes- we will also make a further analysis to evaluate the differences between the answers obtained via on-site and digital media; analyzing in the first part the variation among the punctuation assigned to the problems and the proposals, and in the second the number of open contributions made, and finally, the number of entered commutes.

The sample selected for this work, with the variations indicated over the first case of adjustment, slightly exceed the 1,000 persons (Table 3) of both sexes and over 16 years of age. Even if isolated, rigorous conclusions for the municipalities analyzed could not be inferred, the additional results have already got enough robustness for the extraction of relevant data.

Regarding the surveys made for the Transboundary Plan, taking into account the total population of over 16 years of age, residing in each of the municipalities and the area of study, the participation of a $0.29 \%$ of the residents in the surroundings of the Minho River, with proportional distribution according to gender, age, and municipality, entails an adequate sample in order to evaluate the commutes between both countries (Table 3).

Table 3. Number of participants (from various municipalities and Vale do Minho Transfronteirizo) in the different surveys that were conducted

\begin{tabular}{|l|l|l|l|}
\hline & \multicolumn{1}{|c|}{ Face to Face } & \multicolumn{1}{c|}{ On-Line } & \multicolumn{1}{c|}{ TOTAL } \\
\hline Caldas de Reis & 46 & 94 & 140 \\
\hline Silleda & 58 & 67 & 125 \\
\hline Soutomaior & 45 & 120 & 165 \\
\hline Pazos de Borben & 14 & 35 & 49 \\
\hline Covelo & 35 & 27 & 62 \\
\hline $\begin{array}{l}\text { Vale do Miño } \\
\text { Transfronteirizo }\end{array}$ & 316 & 191 & 507 \\
\hline & $\mathbf{5 1 4}$ & $\mathbf{5 3 4}$ & $\mathbf{1 0 4 8}$ \\
\hline
\end{tabular}

Although it will further be explained in detail, it is convenient to mention that at this point a higher rate of interest of the population was detected according to the proximity of the subject dealt with. That is, a lower dissemination effort was necessary in social networks for the surveys of a municipality, than those made in the transboundary territory, since the territory was more extensive, the interest in the answers was lower (Table 4).

\section{COMPARATIVE ANALYSIS OF RESULTS}

As was previously mentioned, the three blocks of responses will be taken into consideration: the qualitative valuations, the open-ended questions, and the registration of commutes. 
Table 4. Percentage (\%) of survey participation regarding current population above 16 years of age, in different municipalities and Vale do Miño Transfronteirizo

\begin{tabular}{|l|l|l|l|l|}
\hline & \multicolumn{1}{|c|}{ \% Face to Face } & \multicolumn{1}{c|}{ \% On-Line } & \multicolumn{1}{c|}{ \% TOTAL } & Media Broadcast \\
\hline Caldas de Reis & $0,54 \%$ & $1,10 \%$ & $1,64 \%$ & Medium \\
\hline Silleda & $0,76 \%$ & $0,88 \%$ & $1,64 \%$ & Medium \\
\hline Soutomaior & $0,75 \%$ & $1,99 \%$ & $2,74 \%$ & Medium \\
\hline Pazos de Borben & $0,54 \%$ & $1,35 \%$ & $1,89 \%$ & Low \\
\hline Covelo & $1,56 \%$ & $1,20 \%$ & $2,76 \%$ & Medium \\
\hline $\begin{array}{l}\text { Vale do Miño } \\
\text { Transfronteirizo }\end{array}$ & $0,18 \%$ & $0,11 \%$ & $0,29 \%$ & High \\
\hline
\end{tabular}

The qualitative valuations allow the formulating team to analyze both the existing supply and demand. On the one hand, based on previous work, those situations which normally create conflicts in terms of mobility are pointed out (lack of signaling, bad quality infrastructure, excessive traffic, among others). Similarly, the assessment of a series of possible interventions is requested (improvements to the bicycle lane, footpath, increasing of roads, among others). Both the analysis questions about the existing supply, as those that refer to projects, are readjusted based on interviews with the key actors of each municipality or area.

In these questions, an answer ranging between 0 and 10 is possible, depending on the degree of concern that exists about a specific problem, and on the level of acceptance of the proposals. The existing variations between on-line and on-site questions (Table 5) are relatively small and are reduced as the number of people surveyed increases (in the case of the Mobility Plans analyzed, the greater differences are found in the smaller municipalities) albeit, as of a hundred answers, variations are usually scarce.

Table 5. Differences detected in the valuation of problems between the on-site and on-line survey, in different municipalities and Vale do Miño Transfronteirizo

\begin{tabular}{|l|l|l|l|}
\hline & \multicolumn{1}{|c|}{ Average Difference } & \multicolumn{1}{c|}{ Maximum Difference } & Best Opinion \\
\hline Caldas de Reis & 0,44 & 1,2 & 8,2 \\
\hline Silleda & 0,73 & 1,7 & 7,5 \\
\hline Soutomaior & 0,53 & 1,3 & 8,1 \\
\hline Pazos de Borbén & 1,16 & 2,3 & 9,4 \\
\hline Covelo & 1,06 & 2,7 & 9,1 \\
\hline $\begin{array}{l}\text { Vale do Miño } \\
\text { Transfronteirizo }\end{array}$ & 0,64 & 1,1 & 7,7 \\
\hline
\end{tabular}

At a study level, taking into account the global number of surveys, the most significant aspect is that the differences always point in the same direction. The degree of concern for the present state is lower, and the acceptance of proposals is higher, in the case of on-site compared to on-line surveys where, with hardly any global variations, a more critical attitude of the citizens can be observed.

The second part of the survey enables open contributions (regarding both the acts that are considered to be a priority, as well as the suggestions related to the mobility plan or the strategic 
vision of the municipality). These questions, which are grouped in common contents, really increase substantially in the on-line surveys. In this sense we believe that the best willingness and interest in answering the surveys, predisposes towards a proactive effort, even if, a more critical vision in the digital surveys is perceived.

Similarly, as was pointed out, the scale of proximity offered by the municipal area enables to have a greater contribution in this sense. The submissions allow the concretion of a space, a road, or the relationship among different neighborhoods. On the contrary, an extensive territorial area, with multiple municipalities, and differentiated cultural realities, but with indisputable similarities, reduced the number of contributions received.

The third and final subsection, is the referent to the registration of commuters, with an origin-destination matrix, which is the fundamental value for the implementation of the urban mobility plans. To define the possible answers, in the municipal plans, all the parishes of the municipality (neighborhoods) were included, as well as the adjacent municipalities, and the main attractor cities (Table 6).

Table 6. Number of proposals and other opinions in open questions per completed survey in different municipalities and Vale do Miño Transfronteirizo

\begin{tabular}{|l|l|l|l|}
\hline \multicolumn{1}{|c|}{ OPEN QUESTIONS } & \multicolumn{1}{c|}{ Proposals } & \multicolumn{1}{c|}{ Other Opinions } & \multicolumn{1}{c|}{ TOTAL } \\
\hline Caldas de Reis & 2,14 & 1,67 & 0,47 \\
\hline Silleda & 1,71 & 1,24 & 0,47 \\
\hline Soutomaior & 1,86 & 1,39 & 0,47 \\
\hline Pazos de Borben & 1,69 & 1,33 & 0,37 \\
\hline Covelo & 1,32 & 0,85 & 0,47 \\
\hline Vale do Miño Transfronteirizo & 1,04 & 0,87 & 0,17 \\
\hline
\end{tabular}

In this case the number of contributions was larger in the on-site surveys, having a media between 2.8 and 3.9 commutes per person interviewed. This was the case of Silleda. While in the on-line participation the media is between 2.0 and 2.9 commutes, without a significant difference between the individual municipalities.

This data will help to legitimize, to a large extent, the validity of the digital participation in this type of studies, as the differences in results are not relevant (Table 7). In any case, we can observe the contradictions between the information received on-site, much more detailed and explained, and the information obtained through the on-line surveys, which have a more generic bias on which it is not possible to impinge.

We also find differences related to the number of trips stated on the on-line participation, and those stated on the on-site participation. Thus, we analyze the percentage of movements made from the area of study towards other municipalities (and vice-versa). In this sense, in the on-site survey a greater permanence is detected than in the movements collected in the on-line one. This is due to the participation of residents who work away from the given municipality (Table 8).

In the case of the transboundary mobility this data refers to a wider area and only answers that implied transboundary commutes were accepted. For their statistical incorporation it has been opted to consider as internal those commutes to municipalities of both margins of the Miño River, and as external the remaining ones. In this case there are a significant number due to the effect of the territorial attraction of Oporto and Vigo (additional to Viana do Castelo, and Santiago de Compostela, in a lower scale). 
Table 7. Number of commutes according to the type of survey completed in different municipalities and Vale do Miño Transfronteirizo

\begin{tabular}{|l|l|l|l|}
\hline \multicolumn{1}{|c|}{ JOURNEYS } & \multicolumn{1}{c|}{ Face to Face } & \multicolumn{1}{c|}{ On-Line } & \multicolumn{1}{c|}{ TOTAL } \\
\hline Caldas de Reis & 3,7 & 2,2 & 2,7 \\
\hline Silleda & 3,6 & 2,2 & 2,8 \\
\hline Soutomaior & 3,2 & 2,4 & 2,6 \\
\hline Pazos de Borben & 2,5 & 2,9 & 2,8 \\
\hline Covelo & 3,3 & 2,0 & 2,7 \\
\hline $\begin{array}{l}\text { Vale do Miño } \\
\text { Transfronteirizo* }\end{array}$ & 3,2 & 2,4 & 2,8 \\
\hline & $\mathbf{2 , 7}$ & $\mathbf{2 , 3}$ & $\mathbf{2 , 7}$ \\
\hline
\end{tabular}

Table 8. Percentage of movements made with a destination away from the area of study in the on-site survey

\begin{tabular}{|l|l|l|l|}
\hline & $\begin{array}{c}\text { \% Departure From } \\
\text { Domain in the On-Site } \\
\text { Survey }\end{array}$ & $\begin{array}{c}\text { \% Departure From } \\
\text { Domain in the On-Line } \\
\text { Survey }\end{array}$ & $\begin{array}{c}\text { \% Departure From Total } \\
\text { Domain (On-Site + On- } \\
\text { Line) }\end{array}$ \\
\hline Caldas de Reis & $26,16 \%$ & $59,22 \%$ & $44,18 \%$ \\
\hline Silleda & $22,97 \%$ & $44,83 \%$ & $31,62 \%$ \\
\hline Soutomaior & $10,88 \%$ & $59,38 \%$ & $42,99 \%$ \\
\hline Pazos de Borben & $57,14 \%$ & $78,43 \%$ & $72,99 \%$ \\
\hline Covelo & $50,88 \%$ & $45,45 \%$ & $49,11 \%$ \\
\hline
\end{tabular}

\section{MECHANISMS OF DISSEMINATION AND REPRESENTATION}

These surveys, of an anonymous nature, besides collecting the different transboundary commutes (Figure 4) made by a single person in a specific period, integrate a series of additional data about these commutes, such as origin, destination, means of transportation, reason, or departure and return times. Therefore, each of these points of origin and destination enable the elaboration of maps with disaggregated information which turn out to be very useful for public explanations about the behavior of the citizens.

In this way, the data acquires a visibility that, especially at a global level, enables the immediate identification of the attractor centers of the analyzed area. For their elaboration it was necessary to incorporate an algorithm which would allow the automation of the representation of the points of origin and destination, as there are over 5,400 points.

In order to do so, a double system of geo-referentiation is established. Both the attractor centers, as well as each of the settlements have coordinates that locate the first of the site points. As the surveys are completed, the new points are created via a random system with a circular basis and a variable radius, according to the size of the settlement or attractor center.

The elaboration of these maps is not openly available yet, although once the elaboration of the set of mobility plans is completed, its dissemination is expected to be done through a viewer of the displacement maps by municipality, including each of the main parameters obtained - gender, means of transportation, reason, and frequency.

In the web page itself, where the surveys were made, the main tables and charts obtained were published in a static way, as well as the most relevant data upon which the mobility plans are being 
Figure 4. Diagram of transboundary commutes according to purchasing purposes, in the analyzed area. We distinguish between internal (on the left) and external (on the right) displacements, and also between the reasons for the journeys (yellow for superstores, orange for small shops, violet for markets and green for petrol stations). (Transboundary Minho). @ 2019, Author.

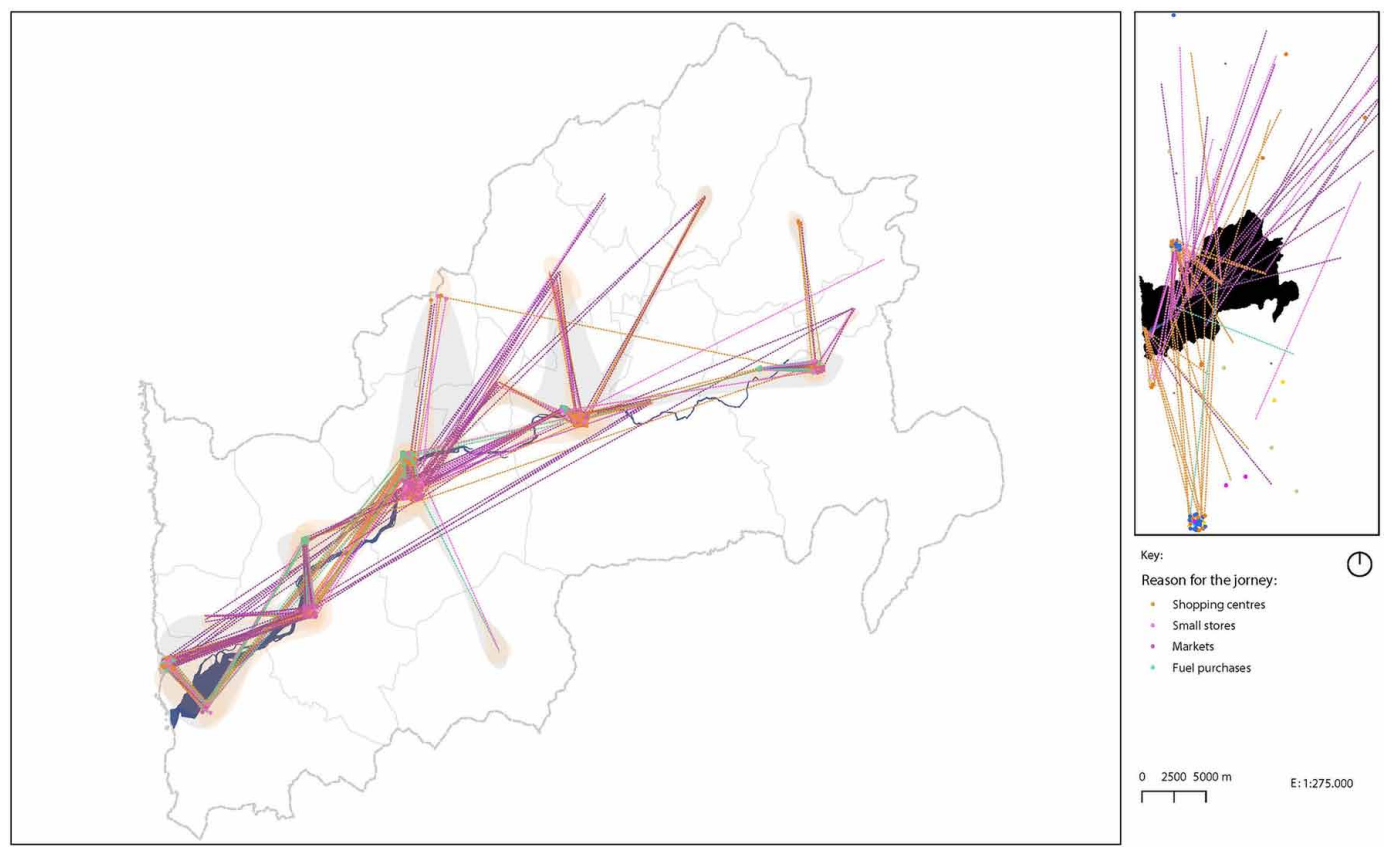

made, even if the most important contributions in the final dissemination process are the ones that refer to the projects that are being raised.

In any case, given the scarce presence of social groups in the participation tables that were formed, the usage of own channels for the dissemination of the information, and the obtainment of feedback from the citizens, turned out to be more important than expected. Especially the survey, mostly concise but as open spaces for private contributions, which enabled to get adequate direct information in each of the plans that were made.

Having such a short period of time, and a saturation of reasons, the use of social networks was limited to the local structures, nevertheless, as was previously mentioned, the final information of each municipality is being posted on a local website, which actually is the same one that was used to make the surveys.

This mechanism of dissemination is raised for the isolated comprehension of the data obtained, but it becomes more relevant when compared to the measures drawn in other municipalities. This is a relevant fact as we believe that, to a great extent, our perception of urban spaces has three focus points: established habits, the comparison to the other, and 'mainstream' concerns.

In the first case, the different mobility plans, have always been focused on a reduction on the dependency of the private vehicle, face the habits of some users for whom their memories are associated to driving their cars with freedom and a total priority over public spaces. Reversing this situation is complex by itself, as it always falls on the subjective. It is thus that the data that is shown tries to demonstrate the non-dependency on the private vehicle, bringing forth data such as distance and time between attractor points, as well as other proprietary data which, from an 'objective' vision, can promote the modification of habits of the residents.

But it is the second case, the comparison to the other, the one that allows us to view more honestly our own shortages, and to set the objectives for a future urban transformation, having a similar city-wise scale as reference. In this case, some individual details, such as the surface of public 
space of the urban land assigned for the private vehicle, seem even more serious when compared to other similar municipalities. The same happens with the data of parking spaces rotation, or available spaces in the streets.

The third case that was mentioned, which we call 'mainstream' concerns, helps to focus on additional topics which allows a deeper and broader discourse. This strategy is valid, for instance, when incorporating the gender vision in the Transboundary Plan, or the introduction of healthy habits when planning minor municipalities. Both contributions have been recurrent since several years ago, but it is only now when they lead the way to articulate, at a communications level, a broader discourse in the transformation of the towns.

Finally, it is noteworthy to mention a residual fact to the process itself which entailed important information and interaction. The indirect contributions in social networks, mainly comments on Facebook about critical pages with the municipal governments, turned out to be relevant to detect controversies and come up with solutions to specific problems, barely mentioned in any of the used mechanisms (workshops and semi-structured interviews, additional to on-site and on-line surveys).

\section{CONCLUSION}

Throughout the previous pages we have read the description of data, processes and comparisons between five plans of municipal mobility, and a territorial plan (and transboundary). Neither the populations, nor the locations, or the departure situations converge. Nevertheless, the processes, methods, and tools have common characteristics which help to demonstrate the contributions of the work done, and also some opportunities for improvement.

Starting with the latter, a process with such a meaningful digital component needs trustworthiness in the previous sources, which is not always real. At different points we have found out-of-date information - extracted from reliable sources - or even minor mistakes which would not happen were the collection of data made specifically for the study. This situation also affects data which are grouped in pre-established ranges - such as traffic intensities - as the shades could make the resolutions different.

Regarding the comparative process between having on-line and on-site surveys, we have detected an important disparity between the application moment of the surveys - in schedules, days of the week, or even climate conditions - which could mean significant changes when the sample is so reduced and it is considered only to be a referent of the tendencies. In this sense, the on-line surveys turned out to be more reliable and less susceptible to be altered by these factors.

Finally, within the possibilities of improvement, it was also proved that the involvement of the citizenship for participation and low-scale processes turned out to be more intense -such as the municipal mobility plans- when facing processes that comprise more extensive areas, as is the case of the Minho River. For the latter case, Facebook publicity was used, reaching, according to its data, over 20,000 interested users on both sides of the border. Although this does not mean having an improvement in the data of participation (quite less than the ones obtained in the municipalities).

The positive contributions that can be drawn from this process can be framed following the description of the document: a first stage of data collection, a second one of participation process, and finally, one of innovation in participation mechanisms.

In order to collect data, despite the existing differences in international projects, it is feasible to obtain data that are comparable by downloading them from open sources -legal and free. The lack of a common administrative framework, and the inexact date of data collection, reduce their possibilities in the face of the studies done only in Spain. Such is the case of the mobility plans in small municipalities, nevertheless, with the available sources it is feasible to reduce the field work, almost to a minimum. 
The participation process is the one that enables to get ampler conclusions based on-more than one thousand surveys made, with a similar number of on-line and on-site surveys (534 for the former, and 514 for the latter). As was pointed out, it can be proved that variations are not especially significant, and that, in most of the cases, they follow a similar pattern. They have a more critical valuation with the current situation in the on-site surveys in small municipalities -where there is a higher implication- and even more generous in the case of the transboundary plan - where the opinions are of greater scale, and thus, there is less personal implication (Figure 5).

Figure 5. Variation of the median punctuation of the surveys made regarding the current mobility state, in the different municipalities and transboundary Minho. ( ) 2019, Author.

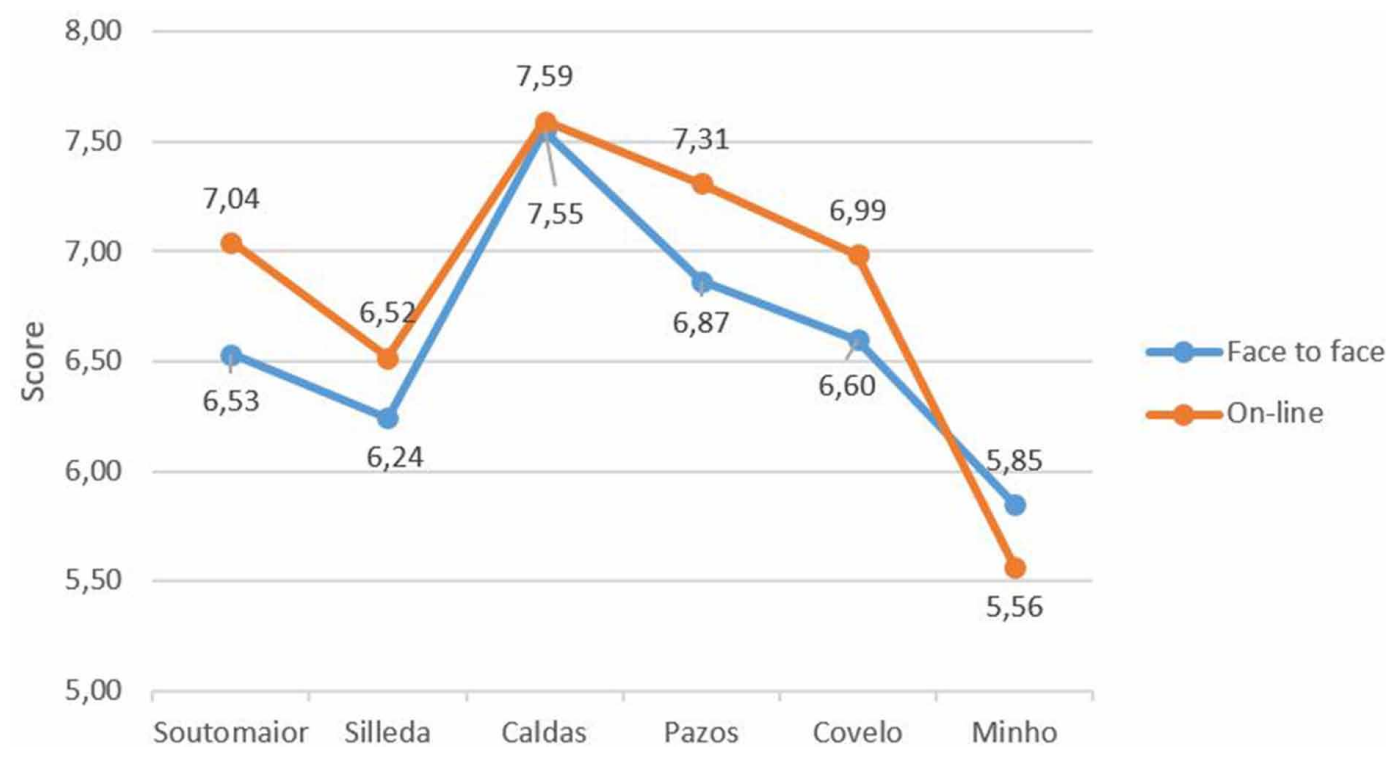

Lastly, regarding the innovation in participation processes through digital media, there was a noticeable improvement in understanding previous data, as well as in the results obtained. This was done through their permanent and connected web location, with the social networks of the different municipalities and interested associations.

This process of urban planning, in the analyzed mobility area, in a shrinking municipality or in an area with stagnated population growth, enables and stimulates to incorporate digital tools for its development. This issue was already raised in the initial hypothesis.

These tools improve, by far, both the collection stage, as well as the participation and dissemination. All these, along with the decision-making tools based on pre-established parameters, allows the digital component in urban planning, to increase exponentially over time. 


\section{REFERENCES}

Burdett, R. (2008). The endless city. London: Phaidon.

Carballo Lomba, A. (2015). A (in)mobilidade transfronteriza: a raia do Minho. In en la Investigacion peninsular: temáticas y enfoques contemporaneos. Santiago de Compostela: USC.

Corburn, J. (2009). Toward the Healthy City. People, Places, and the Politics of Urban Planning. The MIT Press. doi:10.7551/mitpress/7583.001.0001

Dalda, J. L., Docampo, M., \& Harguindey, J. (2006). Cidade Difusa en Galicia. Snatiago de Compostela, España: Dirección Xeral de Urbanismo. Xunta de Galicia.

Domingues, A. (2009). A Rua da Estrada. Porto, Portugal: Dafne Editora.

Ezquiaga, J. M., \& Alfaya, L. (2011). Transformaciones Urbanas Sostenibles. Vigo: Universidad Internacional Menendez Pelayo.

Harguindey, J. G. (2014). El Sistema Urbano en el noroeste de España (Tesis Doctoral). UDC. http://hdl.handle. net/2183/15433

Healey, P. (2010). Making Better Places. The Planning Project in the Twenty-First Century. London, UK: Palgrave Macmillan. doi:10.1007/978-1-137-01379-8

Holl, S. (2009). Urbanisms. Working with Doubt. New York: Princeton Architectural Press.

Lois, R. C., \& Pino, D. (2015). A Galicia urbana. Vigo, España: Edicións Xerais de Galicia.

Palmeiro, J. M., \& Pazos, M. (2008). The Eurorregio Galicia-Northern Portugal: A look to mobility from the Iberian context. Estudios Geográficos, 69(264). doi:10.3989/egeogr.2008.i264.86

Pozueta, J., Lamíquiz, F. J., \& Porto, M. (2009). La ciudad paseable. Madrid, España: CEDEX.

Richardson, H. W., \& Woon Nam, C. (2014). Shrinking cities. A global perspective. London: Regional Studies Assotiation. doi:10.4324/9780203079768

Rueda, S., de Cáceres, R., Cuchí, A., \& Brau, L. (2012). El Urbanismo Ecológico. Su aplicación en el diseño de un ecobarrio en Figueres. Barcelona, España: Agencia de Ecología Urbana de Barcelona.

Ryan, B. D. (2017). The Largest Art. A Measured Manifesto for a Plural Urbanism. The MIT Press. doi:10.7551/ mitpress/10876.001.0001

Sumantran, V., Fine, C. H., \& Gonsalvez, D. J. A. (2017). Faster, Smarter, Greener. The future of the car and urban mobility. The MIT Press. doi:10.7551/mitpress/11188.001.0001 
Luciano Gonzalez Alfaya is an architect having graduated from the University of A Coruña with a specialization in Urban Planning. He has a Master's Degree in Planning and Territorial Strategies from the Faculty of Geography at the University of Santiago de Compostela. He is currently a lecturer of Urban Planning at the San Jorge University (A Coruña) and is a member of the Urban Recycling Research Group at the University of Granada. Previously, he was a lecturer at TEC de Monterrey in Mexico (2014 and 2015), at College of Management in Israel (2013), at the University of A Coruña (2009-2013) and Assistant in the Urban Planning Master course at the University of Edinburgh (2009). He was also a guest professor or speaker at other several Universities in Europe and Latin America. In 2018 he received the XIV Spanish Biennial of Architecture and Urbanism Award for the Urban Strategy 'Habitat Saludable' for Ponteareas, Spain. In 2009 he received first prize in Europan 10 for the revitalization of the Praga Polnoc neighborhood in Warsaw (Poland), a Special Mention in the Arquia / Proxima Prize and the Territorial Ordination Award of the COAG for the project "A Cidade dos Barrios" in A Coruña.

Patricia Muniz is a PhD Architect from "Universidad de A Coruña". Master's Degree, "Metropolis in Architecture and Urban Culture", from "Universitat Politécnica de Catalunya", in 2009. She is involved in architecture and urban projects through Estudio MMASA. She is a Communication Strategic Consultant for urbanism and architecture and has been involved in different investigation projects and various specialized publications and conferences. In regard to Land Planning she has participated in the development of "Urban Strategy for Sustainable and Integrated Development in Ponteareas", and in many other studies related to mobility.

David Wilkes is a graduate in Geography, from "Universidade de Santiago de Compostela", in 2005. Master's Degree in "Local Administration", in 2007, and Postgraduate Degree in "Land Development", in 2005, both from "Universidade de Santiago de Compostela". For the past 12 years he has been involved in many projects related to Land Planning and Development in Galicia and Namibia.

Antia Martinez is an architect, graduated from "Universidad de A Coruña" in 2002, and Joint Graduate from Harbin Institute of Technology (China) in 2016. She has also coursed the III Workshop of Citizen Strategies for Times of Crisis, in 2014. Since 2017 she collaborates with MMASA Studio and has been involved in the development of various urban projects.

Camilo Fernandez is a graduate in Sociology, from "Universidad de A Coruña" in 2006. Urbanism High Technician, from "Escola Galega de Administración Pública", in 2007. For the past 12 years he has been involved in the development of socio-economic studies, and management of public participation dynamics related to urban and land planning. 